\title{
Sub-microscopic infections and long-term recrudescence of Plasmodium falciparum in Mozambican pregnant women
} Alfredo Mayor*1,2, Elisa Serra-Casas,2, Azucena Bardají1,2, Sergi Sanz ${ }^{1}$, Laura Puyol ${ }^{1}$, Pau Cisteró1, Betuel Sigauque ${ }^{2,3}$, Inacio Mandomando ${ }^{1,2,3}$, John J Aponte ${ }^{1,2}$, Pedro L Alonso ${ }^{1,2}$ and Clara Menéndez ${ }^{1,2}$

Address: ${ }^{1}$ Centre de Recerca en Salut Internacional de Barcelona, Hospital Clínic/Institut d'Investigacions Biomèdiques August Pi i Sunyer, Universitat de Barcelona, Rosselló 132, E-08036 Barcelona, Spain, ${ }^{2}$ Centro de Investigação em Saúde da Manhiça (CISM), Maputo, Mozambique and ${ }^{3}$ Direcção Nacional de Saúde/Instituto Nacional de Saúde, Ministerio de Saúde, Maputo, Mozambique

Email: Alfredo Mayor* - agmayor@clinic.ub.es; Elisa Serra-Casas - elserra@clinic.ub.es; Azucena Bardají - abardaji@clinic.ub.es; Sergi Sanz - ssanz@clinic.ub.es; Laura Puyol - lpuyol@clinic.ub.es; Pau Cisteró - pau.cistero@cresib.cat; Betuel Sigauque - betuel.sigauque@manhica.net; Inacio Mandomando - inacio.mandomando@manhica.net; John J Aponte - jjairo@clinic.ub.es; Pedro L Alonso - palonso@clinic.ub.es; Clara Menéndez - menendez@clinic.ub.es

* Corresponding author

Published: 9 January 2009

Malaria Journal 2009, 8:9 doi:10.1 186/1475-2875-8-9
Received: 4 August 2008

Accepted: 9 January 2009

This article is available from: http://www.malariajournal.com/content/8/I/9

(C) 2009 Mayor et al; licensee BioMed Central Ltd.

This is an Open Access article distributed under the terms of the Creative Commons Attribution License (http://creativecommons.org/licenses/by/2.0), which permits unrestricted use, distribution, and reproduction in any medium, provided the original work is properly cited.

\begin{abstract}
Background: Control of malaria in pregnancy remains a public health challenge. Improvements in its correct diagnosis and the adequacy of protocols to evaluate anti-malarial drug efficacy in pregnancy, are essential to achieve this goal.

Methods: The presence of Plasmodium falciparum was assessed by real-time (RT) PCR in 284 blood samples from pregnant women with clinical complaints suggestive of malaria, attending the maternity clinic of a Mozambican rural hospital. Parasite recrudescences in 33 consecutive paired episodes during the same pregnancy were identified by $m s p /$ and msp2 genotyping.

Results: Prevalence of parasitaemia by microscopy was $5.3 \%$ (I5/284) and $23.2 \%(66 / 284)$ by RTPCR. Sensitivity of microscopy, compared to RT-PCR detection, was $22.7 \%$. Risk of maternal anaemia was higher in PCR-positive women than in PCR-negative women (odds ratio [OR] = I.92, 95\% confidence interval [Cl] 1.09-3.36). Genotyping confirmed that recrudescence after malaria treatment occurred in 7 (21\%) out of 33 pregnant women with consecutive episodes during the same pregnancy (time range between recrudescent episodes: 14 to 187 days).

Conclusion: More accurate and sensitive diagnostic indicators of malaria infection in pregnancy are needed to improve malaria control. Longer follow-up periods than the standard in vivo drug efficacy protocol should be used to assess anti-malarial drug efficacy in pregnancy.
\end{abstract}

\section{Background}

Pregnant women are at higher risk of Plasmodium falciparum infection and disease [1], frequently manifested as maternal anaemia, pre-term delivery and low birth weight
$[2,3]$. Infections during pregnancy need to be eliminated with effective anti-malarials to reduce the burden of disease in mothers and their children. Current guidelines to control malaria in pregnancy in sub-Saharan Africa con- 
sist of prompt and effective case management of malaria illness, combined with prevention of infection and/or disease through insecticide-treated nets (ITNs) and intermittent preventive treatment (IPTp) [4].

Control of malaria in pregnancy remains a challenge due to a number of factors. The low specificity of signs and symptoms $[5,6]$ and the limitations of the techniques to detect $P$. falciparum infections impose serious difficulties in the identification of malaria episodes. Until recently, malaria diagnosis relied on the microscopic detection of Plasmodium on Giemsa-stained blood smears. Lately, circulating antigen [7] and polymerase chain reaction (PCR)-based diagnostic methods [8-12] have been added as malaria diagnostic tools. In malaria endemic areas, PCR allows the identification of a high proportion of pregnant women with $P$. falciparum parasitaemia levels below the threshold of microscopy [8-12]. Real-time PCR (RT-PCR), a more sensitive and specific detection methodology $[13,14]$, has been shown to be useful in predicting adverse outcomes of malaria in pregnancy $[15,16]$.

The declining efficacy of classically recommended antimalarial drugs due to the increase of anti-malarial-resistant $P$. falciparum parasites [17], results in multiple treatment failures and prolonged parasitization of the foetoplacental unit with the subsequent adverse events on mother and child health. New anti-malarial drug combinations are now being recommended to replace the less effective ones for the general population. However, there is limited or non-existent information on the safety and efficacy of these new drug alternatives in pregnancy. Data obtained from in vivo studies in children may not be appropriated for determining anti-malarial treatment efficacy in pregnant women because of differences in host immunity, as well as pharmacokinetics [18-21]. Critical analysis of the in vivo standard methods to measure drug efficacy is essential to correctly monitor drug resistance and evaluate new anti-malarials to be administered in pregnancy.

In this study, a PCR-based approach to assess the impact of sub-microscopic infections on disease manifestation of pregnant women attending the maternity clinic of a rural hospital in Mozambique was used. Genetic characterization of parasites isolated from consecutive episodes during the same pregnancy allowed to determine the extent of parasite recrudescences after anti-malarial treatment.

\section{Methods}

\section{Study area and population}

The study was carried out at the Centro de Investigação em Saúde da Manhiça (CISM) in Manhiça District, southern Mozambique. Adjacent to the CISM is the Manhiça District Hospital (MDH), a 110 bed health facility, which provides curative and preventive services. The characteristics of the area have been described in detail elsewhere [22]. Perennial malaria transmission with some seasonality is mostly attributed to P. falciparum. Anopheles funestus is the main vector, and the estimated entomological inoculation rate for 2002 was 38 infective bites per person per year [23]. The most recent data on the efficacy of sulphadoxine-pyrimethamine (SP) and chloroquine (CQ) in children in this area showed a combined (early and late) treatment failure rate of $53 \%$ for CQ and $17.3 \%$ for SP [24].

\section{Study design}

This study was conducted in the context of a health facility-based descriptive study that aimed to characterize the clinical presentation of malaria in Mozambican pregnant women and to evaluate the adequacy of case management based on clinical complaints [6]. A round-the-clock morbidity surveillance system was established at the Maternity Clinic of the Manhica District Hospital (MDH), as a passive case detection system, for all women attending this clinic with clinical complaints. Pregnant women attending the Maternity Clinic between August 2003 and November 2005, with clinical complaints and who gave verbal informed consent, were asked for information on age, parity, gestational age, and signs and symptoms focused on malaria (axillary temperature $\geq 37.5^{\circ} \mathrm{C}$, referred history of fever in the last 24 hours, pallor, arthromyalgias, headache and/or history of convulsions). This clinical and demographic information was collected onto a standardized questionnaire. A capillary blood sample for quantification of $P$. falciparum parasitaemia and haematocrit, and blood on DNA filter paper (Schleicher \& Schuell number 903 ${ }^{\mathrm{Tm}}$; Dassel, Germany) were collected if at least one of the pre-defined clinical criteria suggestive of malaria was met. A random selection of $10 \%$ of the filter papers collected, and all the available filter papers from women with two consecutive malaria episodes during the same pregnancy, were analysed by RT-PCR.

Following national guidelines at the time of the study, women were treated with SP plus CQ in case of non-complicated malaria, except for the first trimester when CQ alone was given. Oral quinine $(\mathrm{Q})$ for seven days was given as rescue treatment. Women with complicated malaria were admitted at the maternity ward, and treated with parenteral quinine followed by SP. Anaemia was treated with oral ferrous sulphate and folic acid for one month. The study protocol was approved by the National Mozambican Ethics Committee and the Hospital Clinic of Barcelona Ethics Review Committee.

\section{Laboratory methods}

Thick and thin blood films, in duplicate, were stained with Giemsa and read to determine parasite species and 
density of P. falciparum asexual stages per 200 leukocytes, according to standard, quality-controlled procedures [25]. The haematocrit was measured using a microhaematocrit centrifuge and read in a Hawksley (Lancing, UK) haematocrit reader.

\section{Detection of Plasmodium falciparum by real time PCR analysis}

Parasite DNA was extracted from $50 \mu$ l blood on filter paper by using the ABIPrism 6700 Automated Nucleic Acid Work Station (Applied Biosystems), according to the manufacturer's instructions. Negative extraction controls consisting of water or non-infected erythrocytes were included in the process. Purified DNA templates were amplified in an ABI PRISM 7900 HT Real-Time System (Applied Biosystems) following a previously described method [13]. Briefly, a $20 \mu \mathrm{l}$ PCR mixture was performed using $5 \mu$ l of template, $10 \mu$ l of $2 \times$ TaqMan $^{\circledast}$ Universal PCR Master Mix (Applied Biosystems), a 300 nM concentration of each primers specific for $18 \mathrm{~S}$ ribosomal RNA gene of $P$. falciparum, and a $150 \mathrm{nM}$ concentration of probe labelled with 6-carboxy-fluorescein (FAM) as a reporter and 6-carboxytetramethylrhodamine (TAMRA) as a quencher. Amplification and detection were performed under the following conditions: $2 \mathrm{~min}$ at $50^{\circ} \mathrm{C}$, $10 \mathrm{~min}$ at $95^{\circ} \mathrm{C}$, and 40 cycles of $15 \mathrm{~s}$ at $95^{\circ} \mathrm{C}$ and $1 \mathrm{~min}$ at $60^{\circ} \mathrm{C}$. The results were automatically analysed by the ABI Prism SDS2.1 software. Each specimen was run in duplicate. A standard curve was prepared from titrated samples containing known numbers of ring-infected erythrocytes diluted in whole blood. The highest dilution of the curve that gave reproducible results in all the optimization assays was the equivalent to 50 parasites per $\mathrm{ml}$ of blood. The standard curve was run in triplicate for each test. RT-PCR efficiency was validated by comparing the slope of the standard curve to the theoretical optimum of -3.32 which reflects $100 \%$ efficient amplification, and was found to be $-3.21 \pm 0.13, \mathrm{R}^{2}=0.99(n=5)$.

\section{Genotyping of P. falciparum isolates}

Plasmodium falciparum infections from consecutive malaria episodes during the same pregnancy were characterized on the basis of the fragment size of the amplified msp1 (allelic families MAD20, K1 and RO33) and msp2 (allelic families FC27 and 3D7/IC1) loci using a previously described PCR approach [26]. Each band was considered an individual strain. Strains were considered the same if the band had an identical size as determined by migration in a $2.5 \%$ agarose gel. Products from episodes of the same women were run side-by-side to allow for direct size comparison. The frequency distribution of the $m s p 1$ and $m p 2$ alleles circulating in the study area was calculated by measuring the proportion of each detected genotype, as defined into 20-base pair ranges, in 60 isolates from pregnant women [27].

\section{Definitions and statistical methods}

A malaria episode was defined as a P. falciparum parasitaemia of any density, and presence of any sign and/or symptom suggestive of malaria (presence or history of fever in the last 24 hours, headache, arthromyalgias, convulsions, pallor) [6]. Fever was defined as a temperature equal or higher to $37.5^{\circ} \mathrm{C}$, and anaemia as a haematocrit less than 33\%. Peripheral blood P. falciparum infections were grouped into the following categories: a) microscopically confirmed parasitaemia; b) RT-PCR confirmed parasitaemia; c) sub-microscopic infections (negative samples by microscopic examination which gave a RT-PCR positive result); d) no infection (negative by microscopy and RTPCR). In this study, the duration of a single malaria episode was estimated as 28 days so as to differentiate between visits on the same episode and a new episode. Multiplicity of infection (MOI) was defined as the maximum number of $m s p 1 / m s p 2$-amplicons detected in the sample. To eliminate the possibility of misclassifying patients with common $m s p 1$ and $m s p 2$ variants as treatment failures, recrudescence was only considered when all strains in the second episode were present in the previous episode, and no new genotypes were found (i.e., both $m s p 1$ and $m s p 2$ amplification products from the second episode were observed in the previous episode). Infections in the second episode that consisted on different strains not present in the previous episode were designated as new infections. When the second malaria episode contained strains present in the previous episode but also new strains, infections were categorized as mixed [28].

Double data entry, validation, and cleaning were done using Microsoft Visual FoxPro 5.0, and statistical analysis was performed using STATA.9 (STATA corporation, College Station, TX, USA). To evaluate the association between the presence of signs and symptoms suggestive of malaria, age, parity, gestational age, number of previous malaria episodes and season with parasitaemia, univariate logistic regression models were used. Sensitivity and specificity of microscopic determination was calculated considering RT-PCR as the gold standard. The cumulative probability of two parasites in two independent episodes being by chance the same for a particular 2-loci genotype was calculated from the frequencies of $m s p 1$ and $m s p 2$ genotypes detected in 60 pregnant women [27]. Days between episodes and multiplicity of infection (MOI) were compared by t Student's test. Monte Carlo permutation test with 1,000 random permutations was performed for each comparison to obtain a more robust estimation of the $p$-value [29]. A permutated $p$-value $<0.05$ was considered statistically significant. 


\section{Results}

\section{Detection of malaria infection}

During the study period (August 2003-November 2005), 3,129 filter papers corresponding to first visits with criteria for blood collection and complete laboratory results were collected from pregnant women attending the MDH. Three hundred out of these samples were randomly selected. Sixteen filter papers were not found. Among the women from whom the 284 filter papers were available, $70.9 \%$ (200/282) were 20-34 years of age, 59.4\% (168/ 283) were in their second to fourth pregnancies, and $48.2 \%(137 / 284)$ had anaemia.

Of the 284 women, 15 (5.3\%) and 66 (23.2\%) had malaria parasitaemia as detected by microscopy and RTPCR, respectively. Fifty-one (18.9\%) of the 269 women found to be aparasitaemic by microscopy were positive by RT-PCR (sub-microscopic infections). Compared with RTPCR detection, microscopy showed a sensitivity of $22.7 \%$. Prevalence of $P$. falciparum malaria, both by microscopy and RT-PCR, was equal across age and parity groups (Table 1 and Table 2). Prevalence of sub-microscopic infections $(\mathrm{n}=51)$ was not statistically different across maternal age $(p=1.00)$, gestational age $(p=1.00)$ and gravidity group $(\mathrm{p}=0.68)$. Infections detected by RT-PCR were more prevalent among women in the third trimester of pregnancy than among those in the first and second trimester (Table 2), although estimates were not statistically significant $(\mathrm{p}=0.082)$. This trend was not found in infections detected by microscopy (Table 1).

\section{Malaria infection and clinical presentation}

There was no evidence of an association between signs or symptoms suggestive of malaria and the presence of microscopically detected peripheral malaria (Table 1). Risk of maternal anaemia was higher in women with RTPCR detected parasitaemina than in women with a negative RT-PCR result (Table 2, OR $=1.92,95 \%$ CI 1.09-3.36, $\mathrm{p}=0.026)$. Women with sub-microscopic infections also had a statistically significant higher risk of anaemia compared with women with negative microscopy and RT-PCR test $(\mathrm{OR}=2.80,95 \% \mathrm{CI} 1.46-5.38, \mathrm{p}=0.002)$. No other malaria sign or symptom was found to be associated with PCR-detected or sub-microscopic infections.

Table I: Association between parasitaemia, as detected by microscopy, and mother age, pregnancy status and signs/symptoms of malaria.

\begin{tabular}{|c|c|c|c|c|c|c|c|c|}
\hline \multirow[b]{3}{*}{ Variable } & & \multicolumn{4}{|c|}{ Microscopy } & \multirow[b]{3}{*}{ OR } & \multirow[b]{3}{*}{$95 \% \mathrm{Cl}$} & \multirow[b]{3}{*}{ p-value* } \\
\hline & & \multicolumn{2}{|c|}{$\begin{array}{c}\text { negative } \\
\mathrm{n}=269\end{array}$} & \multicolumn{2}{|c|}{$\begin{array}{c}\text { positive } \\
n=15\end{array}$} & & & \\
\hline & & $\mathbf{n}$ & $\%$ & $\mathbf{n}$ & $\%$ & & & \\
\hline \multirow[t]{3}{*}{ Age** } & $<20 y$ & 50 & 19 & 4 & 27 & 1 & & 0.606 \\
\hline & $20-34$ y & 190 & 71 & 10 & 67 & 0.66 & $(0.20 ; 2.19)$ & \\
\hline & $>=35 y$ & 27 & 10 & I & 7 & 0.46 & $(0.05 ; 4.35)$ & \\
\hline \multirow[t]{3}{*}{ Gestational age (weeks) } & $1-12$ & 74 & 28 & 3 & 20 & I & & 0.670 \\
\hline & $13-24$ & 68 & 25 & 3 & 20 & 1.09 & $(0.21 ; 5.58)$ & \\
\hline & $>24$ & 127 & 47 & 9 & 60 & 1.75 & $(0.46 ; 6.66)$ & \\
\hline \multirow{3}{*}{ Parity*** } & 0 & 32 & 12 & 0 & 0 & - & & 0.292 \\
\hline & $1-3$ & 156 & 58 & 12 & 80 & I & & \\
\hline & $>=4$ & 80 & 30 & 3 & 20 & 0.49 & $(0.13 ; 1.78)$ & \\
\hline \multirow[t]{2}{*}{ Season } & Dry & 132 & 49 & 11 & 73 & 1 & & 0.105 \\
\hline & Wet & 137 & 51 & 4 & 27 & 0.35 & $(0.11 ; 1.13)$ & \\
\hline \multirow[t]{2}{*}{ Fever } & No & 248 & 92 & 13 & 87 & 1 & & 0.481 \\
\hline & Yes & 21 & 8 & 2 & 13 & 1.82 & $(0.38 ; 8.59)$ & \\
\hline \multirow[t]{2}{*}{ Fever/history of fever**** } & No & 107 & 40 & 4 & 27 & 1 & & 0.264 \\
\hline & Yes & 161 & 60 & II & 73 & 1.83 & $(0.57 ; 5.89)$ & \\
\hline \multirow[t]{2}{*}{ Arthromyalgia } & No & 63 & 23 & 3 & 20 & 1 & & 0.767 \\
\hline & Yes & 206 & 77 & 12 & 80 & 1.22 & $(0.33 ; 4.47)$ & \\
\hline \multirow[t]{2}{*}{ Headache } & No & 27 & 10 & 4 & 27 & 1 & & 0.089 \\
\hline & Yes & 242 & 90 & 11 & 73 & 0.31 & $(0.09 ; 1.03)$ & \\
\hline \multirow[t]{2}{*}{ Pallor } & No & 255 & 95 & 14 & 93 & 1 & & 1.000 \\
\hline & Yes & 14 & 5 & 1 & 7 & 1.3 & $(0.16 ; 10.61)$ & \\
\hline \multirow[t]{2}{*}{ Anemia } & No & 137 & 51 & 10 & 67 & 1 & & 0.288 \\
\hline & Yes & 132 & 49 & 5 & 33 & 0.52 & $(0.17 ; 1.56)$ & \\
\hline
\end{tabular}

*, Univariate logistic regression model; **, Two data missing; ***, One data missing; OR, Odds ratio; Cl, Confidence interval. 
Table 2: Association between parasitaemia, as detected by RT-PCR, and mother age, pregnancy status and signs/symptoms of malaria.

\begin{tabular}{|c|c|c|c|c|c|c|c|c|}
\hline \multirow[b]{3}{*}{ Variable } & & \multicolumn{4}{|c|}{ PCR } & \multirow[b]{3}{*}{ OR } & \multirow[b]{3}{*}{$95 \% \mathrm{Cl}$} & \multirow[b]{3}{*}{ p-value* } \\
\hline & & \multicolumn{2}{|c|}{$\begin{array}{c}\text { negative } \\
\mathrm{n}=218\end{array}$} & \multicolumn{2}{|c|}{$\begin{array}{c}\text { positive } \\
n=66\end{array}$} & & & \\
\hline & & $\mathbf{n}$ & $\%$ & $\mathbf{n}$ & $\%$ & & & \\
\hline \multirow[t]{3}{*}{$\mathrm{Age}^{* *}$} & $<20 y$ & 38 & 18 & 16 & 24 & I & & 0.480 \\
\hline & $20-34$ y & 156 & 72 & 44 & 67 & 0.67 & $(0.34 ; 1.31)$ & \\
\hline & $>=35 y$ & 22 & 10 & 6 & 9 & 0.65 & $(0.22 ; 1.90)$ & \\
\hline \multirow[t]{3}{*}{ Gestational age (weeks) } & $1-12$ & 64 & 29 & 13 & 20 & I & & 0.082 \\
\hline & $13-24$ & 58 & 27 & 13 & 20 & 1.10 & $(0.47 ; 2.57)$ & \\
\hline & $>24$ & 96 & 44 & 40 & 61 & 2.05 & $(1.02 ; 4.14)$ & \\
\hline \multirow[t]{3}{*}{ Parity*** } & 0 & 28 & 13 & 4 & 6 & I & & 0.094 \\
\hline & $1-3$ & 122 & 56 & 46 & 70 & 2.64 & $(0.88 ; 7.94)$ & \\
\hline & $>=4$ & 67 & 31 & 16 & 24 & 1.67 & $(0.5 I ; 5.45)$ & \\
\hline \multirow[t]{2}{*}{ Season } & Dry & 108 & 50 & 35 & 53 & I & & 0.684 \\
\hline & Wet & 110 & 50 & 31 & 47 & 0.87 & $(0.50 ; \mid .5 I)$ & \\
\hline \multirow[t]{2}{*}{ Fever } & No & 200 & 92 & 61 & 92 & 1 & & 1.000 \\
\hline & Yes & 18 & 8 & 5 & 8 & 0.91 & $(0.32 ; 2.55)$ & \\
\hline \multirow[t]{2}{*}{ Fever/history of fever*** } & No & 84 & 39 & 27 & 41 & 1 & & 0.772 \\
\hline & Yes & 133 & 61 & 39 & 59 & 0.91 & $(0.52 ; 1.60)$ & \\
\hline \multirow[t]{2}{*}{ Arthromyalgia } & No & 55 & 25 & 11 & 17 & I & & 0.176 \\
\hline & Yes & 163 & 75 & 55 & 83 & 1.69 & $(0.82 ; 3.45)$ & \\
\hline \multirow[t]{2}{*}{ Headache } & No & 24 & II & 7 & 11 & 1 & & 1.000 \\
\hline & Yes & 194 & 89 & 59 & 89 & 1.04 & $(0.43 ; 2.54)$ & \\
\hline \multirow[t]{2}{*}{ Pallor } & No & 205 & 94 & 64 & 97 & 1 & & 0.568 \\
\hline & Yes & 13 & 6 & 2 & 3 & 0.49 & $(0.11 ; 2.24)$ & \\
\hline \multirow[t]{2}{*}{ Anemia } & No & 121 & 56 & 26 & 39 & 1 & & 0.026 \\
\hline & Yes & 97 & 44 & 40 & 61 & 1.92 & $(1.09 ; 3.36)$ & \\
\hline
\end{tabular}

*, Univariate logistic regression model; **, Two data missing; ***, One data missing; OR, Odds ratio; $\mathrm{Cl}$, Confidence interval.

\section{Malaria recrudescence in pregnancy}

Eleven $m s p 1$ and 20 msp2 genotypes were found in 60 pregnant women, with allelic frequencies ranging from 0.008 to 0.18 (Figure 1). Four $m s p 1$ and 3 msp2 variants were present at frequencies higher than $10 \%$. The cumulative probability of two independent strains being by chance the same for $m s p 1$ and $m s p 2$ in two different episodes was $0.99 \%$. Given this low probability of repeated occurrence by chance of a particular two-loci genotype in the same patient, coincidence of both $m s p 1$ and $m s p 2$ in consecutive episodes was considered evidence of the same parasite.

Sixty-six filter papers were analysed from 33 women with two consecutive malaria episodes during the same pregnancy (Table 3). Recrudescent infections (isolates sharing the same $m s p 1$ and $m s p 2$ genotypes with no evidence of new infections) occurred in $7(21.2 \%)$ of the 33 women. In $22(66.7 \%)$ of the women, the second episode consisted of $P$. falciparum isolates with $m s p 1$ and $m s p 2$ genotypes not present in the previous episodes (new infections). Mixed infections (both recrudescent and new strains present) were present in $4(12.1 \%)$ of the women.
Mean duration of the interval between consecutive episodes was similar in recrudescent ( 58 days, SD 57.7, range 14-187) and new infections (61.2 days, SD 30, range 20129) ( $\mathrm{p}=0.84)$. No statistical difference was found in the mean multiplicity of infection (MOI) from first $(1.95, \mathrm{SD}$ $0.89)$ and second episodes (1.58, SD 0.75) ( $\mathrm{p}=0.33)$, and from recrudescent $(1.71, \mathrm{SD} 0.48)$ and new infections $(1.76, \mathrm{SD} 0.81)(\mathrm{p}=0.82)$.

\section{Discussion}

This study described the prevalence of P. falciparum infection detected by real time PCR among Mozambican pregnant women attending a rural maternity clinic with clinical complaints suggestive of malaria. These results showed that microscopically detectable $P$. falciparum parasitaemia in peripheral blood is a rather poor indicator of the actual presence of infection in pregnancy, as suggested by the low sensitivity of microscopy as compared to RTPCR (22.7\%) and the high prevalence of sub-microscopically infected women (18.9\%). In other settings, sub-patent malaria infections have been found in up to $55 \%$ of the pregnant women [8-12]. This suggests the existence of a level of host immunity able to restrict parasites to low, 

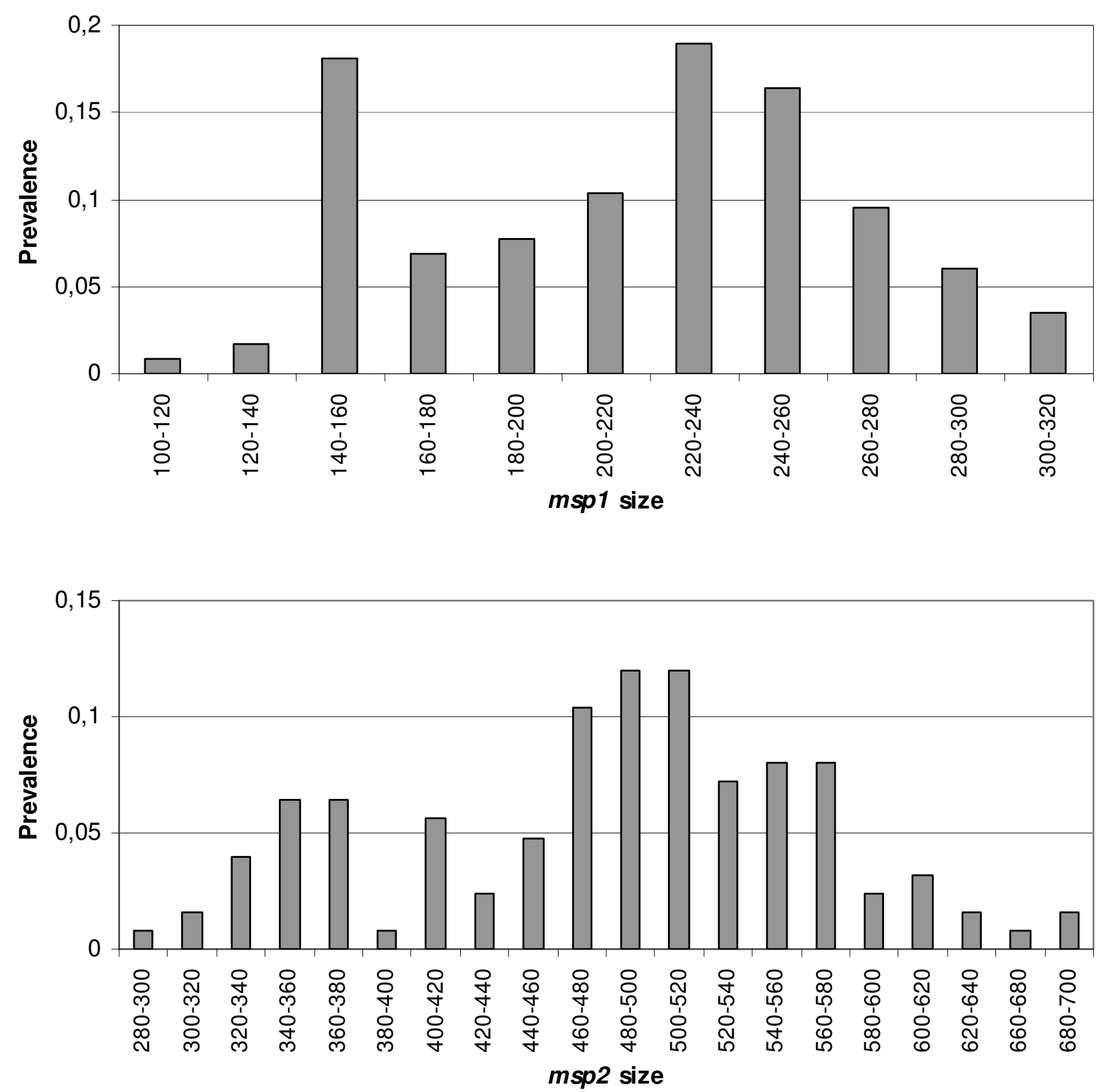

Figure I

Prevalence of $\mathrm{msp} /$ and $\mathbf{m s p 2}$ size variants (in base pairs) in $P$. falciparum parasite population from Manhiça.

microscopically undetectable densities. Alternatively, these low-density infections may represent recently acquired infections which would reach microscopical levels if infection is not treated. Carriage of sub-microscopic infections has been shown to be common also in nonpregnant adults [30,31]. However, the occurrence of microscopically undetected infections are likely to be more clinically relevant during pregnancy, since malaria parasitaemia of any density may have a harmful effect on the pregnant women and her developing foetus $[16,32,33]$.

In this study, the majority of women presenting clinical complaints suggestive of malaria were not infected with $P$. 
Table 3: Malaria genotypes and multiplicity of infection detected in 33 consecutive paired episodes during the same pregnancy.

\begin{tabular}{|c|c|c|c|c|c|c|}
\hline \multirow[b]{3}{*}{ Infection } & & & \multicolumn{2}{|c|}{ msp//msp2 genotypes } & \multirow[b]{3}{*}{$\mathbf{T x}$} & \multirow[b]{3}{*}{ Days } \\
\hline & \multicolumn{2}{|c|}{ MOI } & Same in & Different in & & \\
\hline & Episode I & Episode 2 & both episodes & episode 2 & & \\
\hline \multicolumn{7}{|l|}{ New } \\
\hline & 2 & I & 0 & 1 & $\mathrm{CQ}$ & 20 \\
\hline & 1 & I & 0 & 1 & $\mathrm{CQ}$ & 25 \\
\hline & 2 & I & 0 & 1 & $\mathrm{CQ}+\mathrm{SP}$ & 31 \\
\hline & I & 3 & 0 & 3 & $\mathrm{CQ}$ & 32 \\
\hline & 2 & 2 & 0 & 2 & $\mathrm{CQ}+\mathrm{SP}$ & 35 \\
\hline & 3 & 1 & 0 & 1 & $\mathrm{CQ}+\mathrm{SP}$ & 41 \\
\hline & 3 & 4 & 0 & 4 & $\mathrm{CQ}$ & 47 \\
\hline & I & 2 & 0 & 2 & $\mathrm{CQ}+\mathrm{SP}$ & 47 \\
\hline & 2 & I & 0 & 1 & $Q+S P$ & 49 \\
\hline & 2 & I & 0 & I & $\mathrm{CQ}$ & 50 \\
\hline & 2 & 2 & 0 & 2 & $\mathrm{Q}+\mathrm{SP}$ & 52 \\
\hline & 4 & 2 & 0 & 2 & $\mathrm{CQ}$ & 55 \\
\hline & 1 & I & 0 & 1 & $\mathrm{CQ}+\mathrm{SP}$ & 56 \\
\hline & 1 & 1 & 0 & 1 & $\mathrm{CQ}$ & 59 \\
\hline & 2 & I & 0 & I & $\mathrm{CQ}+\mathrm{SP}$ & 64 \\
\hline & I & 2 & 0 & 2 & $\mathrm{CQ}+\mathrm{SP}$ & 72 \\
\hline & 2 & 1 & 0 & 1 & $\mathrm{CQ}+\mathrm{SP}$ & 77 \\
\hline & 1 & 2 & 0 & 2 & $\mathrm{CQ}+\mathrm{SP}$ & 81 \\
\hline & 4 & 2 & 0 & 2 & $\mathrm{CQ}+\mathrm{SP}$ & 93 \\
\hline & 2 & 2 & 0 & 2 & $\mathrm{CQ}+\mathrm{SP}$ & 116 \\
\hline & 2 & 2 & 0 & 2 & $C Q+S P$ & 117 \\
\hline & 2 & 1 & 0 & 1 & $\mathrm{CQ}$ & 129 \\
\hline \multicolumn{7}{|c|}{ Recrudescent } \\
\hline & I & I & I & 0 & $\mathrm{CQ}$ & 14 \\
\hline & 3 & 2 & 2 & 0 & $\mathrm{CQ}$ & 39 \\
\hline & 2 & 2 & 2 & 0 & $\mathrm{CQ}+\mathrm{SP}$ & 41 \\
\hline & 3 & 2 & 2 & 0 & $\mathrm{CQ}+\mathrm{SP}$ & 41 \\
\hline & 1 & I & I & 0 & $\mathrm{CQ}+\mathrm{SP}$ & 42 \\
\hline & 2 & 2 & 2 & 0 & $\mathrm{CQ}$ & 42 \\
\hline & 3 & 2 & 2 & 0 & $Q$ & 187 \\
\hline \multicolumn{7}{|l|}{ Mixed } \\
\hline & I & 2 & I & I & $\mathrm{Q}$ & 29 \\
\hline & 3 & 2 & 1 & 1 & $\mathrm{CQ}+\mathrm{SP}$ & 38 \\
\hline & 3 & 3 & i & 2 & $\mathrm{CQ}$ & 98 \\
\hline & 3 & 3 & 1 & 2 & $\mathrm{CQ}$ & 122 \\
\hline
\end{tabular}

MOI, Multiplicity of infection; Tx, anti-malarial used to treat episode I; Days, Days between epidodes; Q, Quinine; CQ, Chloroquine; SP, Sulphadoxine-Pyrimethamine.

falciparum, as detected by microscopy $(94.7 \%)$ and even by RT-PCR (76.8\%). Thus, in this context, presumptive malaria treatment would lead to unnecessary exposure to anti-malarial drugs in the majority of pregnant women presenting with "malaria-like" clinical complaints [6]. On the other hand, treatment based on microscopically confirmed malaria episodes only, might lead to under-treatment because of the significant proportion of infections bellow the detection threshold of microscopy. The ability of RT-PCR to detect this additional population of women at risk for malaria infection that were otherwise microscopically negative would contribute effectively to a better management of malaria in pregnancy. However, PCRbased methods require costly reagents and instrumentation that are not widely available in developing countries. Rapid tests that detect parasite-specific antigens [7] may overcome the problem of inadequate diagnosis and treatment. In addition, a more sensitive definition of clinical malaria in pregnancy should also be evaluated. Other symptoms and signs could be considered, since those frequently used to define a malaria episode are poor indicators of $P$. falciparum infection both in pregnant women [6] and non-pregnant adults [31]. 
In this study, anaemia was the only symptom associated with parasitaemia as detected by RT-PCR. This association was not found for microscopical parasitaemia in this subset of samples, maybe due to limitations of the sample size. Women with sub-microscopic infections were also at higher risk of anaemia compared with women with negative microscopy and RT-PCR test, suggesting a role of lowdensity infections in the aetiology of maternal anaemia. A similar association has been found in some studies $[31,34]$, but not in others $[8,10,12,35]$, may be due to differences in the sensitivity of the molecular technique used. The results of this study suggest that low-density asymptomatic infections may significantly increase the risk of becoming anaemic. Alternatively, anaemia may be a consequence of recent high density infections controlled at the time of examination.

PCR-confirmed recrudescences were found in $21 \%$ of the women experiencing two successive episodes during the same pregnancy. The rate of recrudescences found in this study raises important questions for drug efficacy in pregnancy. First, it suggests that the efficacy of anti-malarial drugs during pregnancy may be reduced. This can be due to inadequate drug levels, limited clearing capacity of placental parasites, or to immunosuppresion and physiological changes during pregnancy which are likely to alter the pharmacokinetics of most anti-malarials [18-21,36]. Secondly, these results show that recrudescences of $P$. falciparum parasites during pregnancy can occur as late as 187 days. In other studies, reappearance of parasites has been shown to occur 35, 49, 85 and 119 days after treatment $[37,38]$. In Thailand, recrudescence was detected up to 62 days post-treatment in non pregnant individuals and up to 121 days in pregnant women [27]. Thus, the 28 days standard in vivo test [39] may not be adequate to assess the efficacy of anti-malarial drugs in pregnant women, since it would not detect recrudescences that occur much later. Various alternative assessment times have been used to define treatment failures in anti-malarial drug efficacy studies, ranging from 42 days [40-42] to 63 days [37,38] after treatment. This study suggests that even longer follow-up may be needed during pregnancy to capture all treatment failures. It is essential that these studies include molecular genotyping to distinguish recrudescences from reinfections.

\section{Conclusion}

These results point out two important issues for malaria control during pregnancy; on the one hand, the need to apply more accurate and sensitive measures to detect malaria infections in pregnancy. On the other hand, it might be necessary to extend the follow-up period for in vivo tests to correctly identify anti-malarial drug failures during pregnancy. Appropriate, standardized genotyping methods should be applied to unequivocally identify recrudescent parasites. This is essential to optimize the drug regimens needed to eliminate the plasmodial biomass in pregnant women, and to correctly measure the efficacy of the existing and new anti-malarials to be used in pregnancy.

\section{Competing interests}

The authors declare that they have no competing interests.

\section{Authors' contributions}

AM and ES carried out the molecular genotyping study, the analysis and interpretation of data and prepared the manuscript. LP and PC contributed to the molecular genotyping study and the interpretation of data. SS and JA carried the statistical analysis and helped to draft the manuscript. AB and IM carried out the sample collection and contributed to the analysis and interpretation of data. BS contributed to the interpretation of the data and drafting of the paper. CM and PA conceived and coordinated the study, participated in the analysis and interpretation of the data, and contributed to the preparation of the manuscript. All authors read and approved the final manuscript.

\section{Acknowledgements}

We thank the women participating in the study; and the staff of the Manhiça District Hospital, for their collaboration in the project; the clinical officers, field supervisors an data manager, whose work was important for the successful completion of the study; and Alfons Jiménez and Diana Barrios for their contribution to the molecular analysis of the samples.

The study received financial support from the Banco de Bilbao, Vizcaya, Argentaria Foundation (grant number BBVA 02-0) and the Spanish Ministry of Health (PI0600 16). The Manhiça Health Research Center receives core support from the Spanish Agency for International Cooperation. AM was supported by the Spanish Ministry of Health (Program for the Promotion of Biomedical Research and Health Sciences, Instituto de Salud Carlos III, CP-04/00220). The funding source did not have any involvement in study design, collection, analysis and interpretation of data, writing of the report, or in the decision to submit the paper for publication. The researches are independent from the funders.

\section{References}

I. Diagne N, Rogier C, Cisse B, Trape JF: Incidence of clinical malaria in pregnant women exposed to intense perennial transmission. Trans R Soc Trop Med Hyg 1997, 9 I: I66-I 70.

2. Menendez C, Ordi J, Ismail MR, Ventura PJ, Aponte JJ, Kahigwa E, Font F, Alonso PL: The impact of placental malaria on gestational age and birth weight. J Infect Dis 2000, I 8 I:1740-1745.

3. Brabin B, Prinsen-Geerligs P, Verhoeff F, Kazembe P: Anaemia prevention for reduction of mortality in mothers and children. Trans R Soc Trop Med Hyg 2003, 97:36-38.

4. WHO: A strategic framework for malaria prevention and control during pregnancy in the African region. 2004.

5. Steketee RW, Wirima J, Slutsker L, Khoromana CO, Heymann DL, Breman JG: Malaria treatment and prevention in pregnancy: indications for use and adverse events associated with use of chloroquine or mefloquine. Am J Trop Med Hyg 1996, 55:50-56.

6. Bardaji A, Sigauque B, Romagosa C, Bruni L, Sanz S, Mabunda S, Mandomando I, Aponte J, Sevene E, Alonso PL, Menendez C: Clinical malaria in African pregnant women. Malar J 2008, 7:27.

7. Moody A: Rapid diagnostic tests for malaria parasites. Clin Microbiol Rev 2002, I 5:66-78. 
8. Mockenhaupt FP, Rong B, Till H, Eggelte TA, Beck S, Gyasi-Sarpong C, Thompson WN, Bienzle U: Submicroscopic Plasmodium falciparum infections in pregnancy in Ghana. Trop Med Int Health 2000, 5:167-173.

9. Schleiermacher D, Rogier C, Spiegel A, Tall A, Trape JF, MercereauPuijalon O: Increased multiplicity of Plasmodium falciparum infections and skewed distribution of individual $\mathrm{mspl}$ and msp2 alleles during pregnancy in Ndiop, a Senegalese village with seasonal, mesoendemic malaria. Am J Trop Med Hyg 200I, 64:303-309.

10. Saute F, Menendez C, Mayor A, Aponte J, Gomez-Olive X, Dgedge M, Alonso $\mathrm{P}$ : Malaria in pregnancy in rural Mozambique: the role of parity, submicroscopic and multiple Plasmodium falciparum infections. Trop Med Int Health 2002, 7:19-28.

II. Mayengue PI, Rieth H, Khattab A, Issifou S, Kremsner PG, Klinkert MQ, Ntoumi F: Submicroscopic Plasmodium falciparum infections and multiplicity of infection in matched peripheral, placental and umbilical cord blood samples from Gabonese women. Trop Med Int Health 2004, 9:949-958.

12. Walker-Abbey A, Djokam RR, Eno A, Leke RF, Titanji VP, Fogako J, Sama G, Thuita LH, Beardslee E, Snounou G, Zhou A, Taylor DW: Malaria in pregnant Cameroonian women: the effect of age and gravidity on submicroscopic and mixed-species infections and multiple parasite genotypes. Am J Trop Med Hyg 2005, 72:229-235.

13. Hermsen CC, Telgt DS, Linders EH, Locht LA van de, Eling WM, Mensink EJ, Sauerwein RW: Detection of Plasmodium falciparum malaria parasites in vivo by real-time quantitative PCR. Mol Biochem Parasitol 200I, I I 8:247-25I.

14. Hermsen CC, de Vlas SJ, van Gemert GJ, Telgt DS, Verhage DF, Sauerwein RW: Testing vaccines in human experimental malaria: statistical analysis of parasitemia measured by a quantitative real-time polymerase chain reaction. Am J Trop Med Hyg 2004, 7I:|96-20|.

15. Malhotra I, Dent A, Mungai P, Muchiri E, King CL: Real-time quantitative PCR for determining the burden of Plasmodium falciparum parasites during pregnancy and infancy. J Clin Microbio 2005, 43:3630-3635.

16. Adegnika AA, Verweij JJ, Agnandji ST, Chai SK, Breitling LP, Ramharter M, Frolich M, Issifou S, Kremsner PG, Yazdanbakhsh M: Microscopic and sub-microscopic Plasmodium falciparum infection, but not inflammation caused by infection, is associated with low birth weight. Am J Trop Med Hyg 2006, 75:798-803.

17. White NJ: Antimalarial drug resistance. J Clin Invest 2004, I 1 3: 1084-1092.

18. Na Bangchang K, Davis TM, Looareesuwan S, White NJ, Bunnag D, Karbwang J: Mefloquine pharmacokinetics in pregnant women with acute falciparum malaria. Trans $R$ Soc Trop Med Hyg 1994 88:32I-323.

19. McGready R, Stepniewska K, Edstein MD, Cho T, Gilveray G, Looareesuwan S, White NJ, Nosten F: The pharmacokinetics of atovaquone and proguanil in pregnant women with acute falciparum malaria. Eur J Clin Pharmacol 2003, 59:545-552.

20. McGready R, Stepniewska K, Lindegardh N, Ashley EA, La Y, Singhasivanon P, White NJ, Nosten F: The pharmacokinetics of artemether and lumefantrine in pregnant women with uncomplicated falciparum malaria. Eur J Clin Pharmacol 2006, 62: $|02|-|03|$.

21. McGready R, Stepniewska K, Ward SA, Cho T, Gilveray G Looareesuwan S, White NJ, Nosten F: Pharmacokinetics of dihydroartemisinin following oral artesunate treatment of pregnant women with acute uncomplicated falciparum malaria. Eur J Clin Pharmacol 2006, 62:367-37I.

22. Alonso P, Saute F, Aponte J], Gomez-Olive FX, Nhacolo A, Thomson R, Macete E, Abacassamo FP, Ventura PJ, Bosch X, Menendez C, Dgedge M: Manhica DSS, Mozambique. Population, Health and Survival at INDEPTH Sites 200I, I:189-195.

23. Alonso PL, Sacarlal J, Aponte JJ, Leach A, Macete E, Milman J, Mandomando I, Spiessens B, Guinovart C, Espasa M, Bassat Q, Aide P, OforiAnyinam O, Navia MM, Corachan S, Ceuppens M, Dubois MC Demoitie MA, Dubovsky F, Menendez C, Tornieporth N, Ballou WR, Thompson R, Cohen J: Efficacy of the RTS, S/ASO2A vaccine against Plasmodium falciparum infection and disease in young African children: randomised controlled trial. Lancet 2004, 364: $1411-1420$
24. Abacassamo F, Enosse S, Aponte J], Gomez-Olive FX, Quinto L, Mabunda S, Barreto A, Magnussen P, Ronn AM, Thompson R, Alonso PL: Efficacy of chloroquine, amodiaquine, sulphadoxinepyrimethamine and combination therapy with artesunate in Mozambican children with non-complicated malaria. Trop Med Int Health 2004, 9:200-208.

25. Alonso PL, Smith T, Schellenberg JR, Masanja H, Mwankusye S, Urassa $\mathrm{H}$, Bastos de Azevedo I, Chongela J, Kobero S, Menendez C, et al:: Randomised trial of efficacy of SPf66 vaccine against Plasmodium falciparum malaria in children in southern Tanzania. Lancet 1994, 344: I 175-I I8I.

26. Snounou G, Zhu X, Siripoon N, Jarra W, Thaithong S, Brown KN, Viriyakosol S: Biased distribution of $\mathbf{m s p} I$ and $\mathbf{m s p 2}$ allelic variants in Plasmodium falciparum populations in Thailand. Trans $R$ Soc Trop Med Hyg 1999, 93:369-374.

27. Brockman A, Paul RE, Anderson TJ, Hackford I, Phaiphun L, Looareesuwan S, Nosten F, Day KP: Application of genetic markers to the identification of recrudescent Plasmodium falciparum infections on the northwestern border of Thailand. Am J Trop Med Hyg 1999, 60:14-21.

28. Slater M, Kiggundu M, Dokomajilar C, Kamya MR, Bakyaita N, Talisuna $A$, Rosenthal PJ, Dorsey G: Distinguishing recrudescences from new infections in antimalarial clinical trials: major impact of interpretation of genotyping results on estimates of drug efficacy. Am J Trop Med Hyg 2005, 73:256-262.

29. Good PI: Resampling Methods: A practical guide to data analysis. Boston: Birkhauser; 1999.

30. Bottius E, Guanzirolli A, Trape JF, Rogier C, Konate L, Druilhe P: Malaria: even more chronic in nature than previously thought; evidence for subpatent parasitaemia detectable by the polymerase chain reaction. Trans $R$ Soc Trop Med Hyg 1996, 90:15-19.

31. Mayor A, Aponte J], Fogg C, Saute F, Greenwood B, Dgedge M, Menendez C, Alonso PL: The epidemiology of malaria in adults in a rural area of southern Mozambique. Malar J 2007, 6:3.

32. Mankhambo L, Kanjala M, Rudman S, Lema VM, Rogerson SJ: Evaluation of the OptiMAL rapid antigen test and species-specific PCR to detect placental Plasmodium falciparum infection at delivery. J Clin Microbiol 2002, 40: I55-I58.

33. McGready R, Davison BB, Stepniewska K, Cho T, Shee H, Brockman A, Udomsangpetch R, Looareesuwan S, White NJ, Meshnick SR, Nosten F: The effects of Plasmodium falciparum and $P$. vivax infections on placental histopathology in an area of low malaria transmission. Am J Trop Med Hyg 2004, 70:398-407.

34. Mockenhaupt FP, Ulmen U, von Gaertner C, Bedu-Addo G, Bienzle U: Diagnosis of placental malaria. J Clin Microbiol 2002, 40:306-308.

35. Adam I, A-Elbasit IE, Salih I, Elbashir MI: Submicroscopic Plasmodium falciparum infections during pregnancy, in an area of Sudan with a low intensity of malaria transmission. Ann Trop Med Parasitol 2005, 99:339-344.

36. Green MD, van Eijk AM, Kuile FO van Ter, Ayisi JG, Parise ME, Kager PA, Nahlen BL, Steketee R, Nettey H: Pharmacokinetics of sulfadoxine-pyrimethamine in HIV-infected and uninfected pregnant women in Western Kenya. J Infect Dis 2007, 196: $1403-1408$

37. McGready R, Brockman A, Cho T, Cho D, van Vugt M, Luxemburger C, Chongsuphajaisiddhi T, White NJ, Nosten F: Randomized comparison of mefloquine-artesunate versus quinine in the treatment of multidrug-resistant falciparum malaria in pregnancy. Trans R Soc Trop Med Hyg 2000, 94:689-693.

38. McGready R, Ashley EA, Moo E, Cho T, Barends M, Hutagalung R, Looareesuwan S, White NJ, Nosten F: A randomized comparison of artesunate-atovaquone-proguanil versus quinine in treatment for uncomplicated falciparum malaria during pregnancy. J Infect Dis 2005, 192:846-853.

39. WHO: Monitoring antimalarial drug resistance. 2001

40. McGready R, Cho T, Cho JJ, Simpson JA, Luxemburger C, Dubowitz L, Looareesuwan S, White NJ, Nosten F: Artemisinin derivatives in the treatment of falciparum malaria in pregnancy. Trans $R$ Soc Trop Med Hyg 1998, 92:430-433.

41. McGready R, Cho T, Samuel, Villegas L, Brockman A, van Vugt M, Looareesuwan S, White NJ, Nosten F: Randomized comparison of quinine-clindamycin versus artesunate in the treatment of falciparum malaria in pregnancy. Trans $R$ Soc Trop Med Hyg 200I, 95:65I-656. 
42. McGready R, Cho T, Keo NK, Thwai KL, Villegas L, Looareesuwan S, White NJ, Nosten F: Artemisinin antimalarials in pregnancy: a prospective treatment study of $\mathbf{5 3 9}$ episodes of multidrugresistant Plasmodium falciparum. Clin Infect Dis 200I, 33:2009-2016.

Publish with Bio Med Central and every scientist can read your work free of charge

"BioMed Central will be the most significant development for disseminating the results of biomedical research in our lifetime. " Sir Paul Nurse, Cancer Research UK

Your research papers will be:

- available free of charge to the entire biomedical community

- peer reviewed and published immediately upon acceptance

- cited in PubMed and archived on PubMed Central

- yours - you keep the copyright

Submit your manuscript here:

http://www.biomedcentral.com/info/publishing_adv.asp
BioMedcentral 